\title{
The CarboMedics supra-annular Top Hat valve improves long-term left ventricular mass regression
}

\author{
Victor X. Mosquera, MD, PhD, ${ }^{\mathrm{a}}$ Alberto Bouzas-Mosquera, $\mathrm{MD}, \mathrm{PhD},{ }^{\mathrm{b}}$ Victor Bautista-Hernandez, MD, PhD, ${ }^{\mathrm{a}}$ \\ Francisco Estévez-Cid, MD, ${ }^{\mathrm{a}}$ José M. Herrera-Noreña, MD, PhD, ${ }^{\mathrm{a}}$ Nemesio Alvarez-García, MD, PhD, ${ }^{\mathrm{b}}$ and \\ José J. Cuenca-Castillo, MD
}

\begin{abstract}
Objective: The present study aimed to identify potential differences in hemodynamic performance between the supra-annular CarboMedics Top Hat valve and the intra-annular CarboMedics standard valve in terms of the long-term left ventricular mass reduction and transvalvular gradients.
\end{abstract}

\begin{abstract}
Methods: We retrospectively reviewed a series of 186 consecutive patients who had undergone aortic valve replacement with a small size mechanical prosthesis at our institution from 2003 to 2013, receiving either a CarboMedics Top Hat valve (53 patients, valve size, $21 \mathrm{~mm}$ in $52.8 \%$ and $23 \mathrm{~mm}$ in $47.2 \%$ ) or a CarboMedics standard prosthesis (133 patients, valve size, $19 \mathrm{~mm}$ in $14.3 \%$ and $21 \mathrm{~mm}$ in $85.7 \%$ ).

Results: The in-hospital mortality was $9.4 \%$ and $11.3 \%$ in the Top Hat and standard groups, respectively $(P=.71)$. The mean percentage of left ventricular mass reduction was greater in the Top Hat group $(33 \% \pm$ $15.8 \%$ vs $20.1 \% \pm 16.6 \%, P<.001)$. The mean postoperative peak aortic gradient was lower in the Top Hat group $(19.9 \pm 8.9$ vs $29.6 \pm 8.6 \mathrm{~mm} \mathrm{Hg} ; P<.001)$. Spearman analysis showed a positive correlation between the indexed effective orifice area and the percentage of left ventricular mass reduction (Rho $=+0.65, P=.02$ ). The survival in the Top Hat group was $79.7 \%$ and $71.7 \%$ at 5 and 10 years, respectively. In the standard group, survival was $66.8 \%$ and $61.5 \%$ at 5 and 10 years, respectively (log-rank test, 0.19 ). Cox regression demonstrated severe myocardial hypertrophy (hazard ratio, 2.559; 95\% confidence interval, 1.095-5.981) as one of the independent predictors of survival.
\end{abstract}

Conclusions: The Top Hat valve surpasses hemodynamically the intra-annular valve. We suggest the supraannular Top Hat prosthesis can be especially recommended for patients with a small aortic root and severe myocardial hypertrophy. (J Thorac Cardiovasc Surg 2014;148:2845-53)

Supplemental material is available online.

One of the most vexing problems to be managed in patients undergoing aortic valve replacement (AVR) with a small size mechanical aortic valve is obtaining the best possible hemodynamic results to optimize recovery and survival. Those patients are at high risk of presenting with a patient-prosthesis mismatch (PPM), which can result in greater transvalvular gradients, limited left ventricular (LV) mass regression, and increased early and late morbidity and mortality. ${ }^{1-3}$ Manufacturers have, therefore, developed enhanced-performance supra-annular valves to

\footnotetext{
From the Departments of Cardiac Surgery ${ }^{\mathrm{a}}$ and Cardiology, ${ }^{\mathrm{b}}$ Complejo Hospitalario Universitario de A Coruña, A Coruña, Spain.

Disclosures: Authors have nothing to disclose with regard to commercial support.

Received for publication March 4, 2014; revisions received June 2, 2014; accepted for publication June 6, 2014; available ahead of print Aug 15, 2014.

Address for reprints: Victor X. Mosquera, MD, PhD, Department of Cardiac Surgery, Complejo Hospitalario Universitario de A Coruña, As Xubias no. 84, A Coruña CP 15006, Spain (E-mail: Victor.X.Mosquera.Rodriguez@sergas.es). $0022-5223 / \$ 36.00$

Copyright (c) 2014 by The American Association for Thoracic Surgery http://dx.doi.org/10.1016/j.jtcvs.2014.06.082
}

be implanted above the tissue annulus, such as the CarboMedics Top Hat valve (CarboMedics, Austin, Tex). ${ }^{4-6}$

The aim of the present study was to identify potential differences in hemodynamic performance between the supra-annular CarboMedics Top Hat valve and the intraannular standard CarboMedics valve in terms of longterm LV mass reduction and transvalvular gradients and to describe the early and late clinical outcomes of both valves in patients receiving a small mechanical aortic prosthesis.

\section{METHODS \\ Study Population}

From June 2003 to June 2013, 186 consecutive patients underwent AVR with a small size (size, 19 or $21 \mathrm{~mm}$ ) mechanical aortic prosthesis at our institution. Of the 186 patients, 53 (mean age, $63.7 \pm 8$ years) underwent mechanical AVR with the CarboMedics Top Hat bileaflet valve and were compared with 133 patients (mean age, $61.9 \pm 9.4$ years) who received a standard CarboMedics prosthesis. The institutional review board approved the present study because of the retrospective data retrieval, waiving the need for individual patient consent.

\section{Data Source}

Demographic, clinical, and echocardiographic data collection was accomplished using linked clinical and administrative databases through 


\section{Abbreviations and Acronyms \\ $\mathrm{AVR}=$ aortic valve replacement \\ $\mathrm{EOA}=$ effective orifice area \\ EOA $\mathrm{i}=$ indexed effective orifice area \\ $\mathrm{LV}=$ left ventricular \\ $\mathrm{LVEF}=$ left ventricular ejection fraction \\ PPM = patient-prosthesis mismatch}

the Department of Information Technology of our institution. Only adult patients (age $>18$ years) were considered for the present study.

\section{Echocardiography}

Echocardiograms were performed in the left lateral decubitus position using standard imaging planes according to the American Society of Echocardiography recommendations. ${ }^{7}$ The $\mathrm{LV}$ mass was calculated using the formula by Devereux and colleagues ${ }^{8}$ :

$\mathrm{LV}$ mass $(\mathrm{g})=0.80 \times\{1.04 \times[($ ventricular septal thickness + left ventricular end - diastolic diameter +

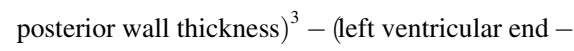
diastolic diameter $\left.\left.)^{3}\right]\right\}+0.6 \mathrm{~g}$

The LV mass was categorized as a sex-specific variable. LV hypertrophy was defined as a LV mass of $\geq 163 \mathrm{~g}$ in women or $\geq 224 \mathrm{~g}$ in men. ${ }^{9} \mathrm{~A}$ LV mass less than these values was considered normal. Severe LV hypertrophy was defined as $\geq 211 \mathrm{~g}$ in women or $\geq 293 \mathrm{~g}$ in men, in accordance with the American Society of Echocardiography recommendations. ${ }^{9}$ LV mass reduction was expressed as a percentage of the basal LV mass to effectively compare the results among the patients:

$$
\begin{aligned}
\mathrm{LV} \text { mass reduction }(\%)= & {[\text { preoperative } \mathrm{LV} \text { mass }(\mathrm{g})-} \\
& \text { preoperative } \mathrm{LV} \text { mass }(\mathrm{g})] / \\
& \text { preoperative } \mathrm{LV} \text { mass }(\mathrm{g}) \times 100
\end{aligned}
$$

The LV ejection fraction (LVEF) was estimated using Teichholz's formula or Simpson's rule. LV systolic dysfunction was defined as a LVEF of $<55 \%$, and severe LV dysfunction was considered as LVEF of $<35 \%$. ${ }^{9}$ LV enlargement was defined as an end-diastolic LV diameter of $\geq 60 \mathrm{~mm}$ in men or $\geq 54 \mathrm{~mm}$ in women. ${ }^{9}$ The presence and severity of aortic stenosis was determined by measuring the peak and mean gradients across the aortic valve by continuous wave Doppler or by calculating the aortic valve area using the continuity equation. ${ }^{10}$ The degree of mitral regurgitation was determined semiquantitatively using continuous wave Doppler and pulsed Doppler quantitative flow methods. ${ }^{11} \mathrm{~A}$ small aortic root was defined as an indexed aortic root diameter of $<1.5 \mathrm{~mm} / \mathrm{m}^{2}$.

The expected effective orifice area (EOA) of each prosthesis size was provided by the manufacturer (Table E1) and confirmed by other investigators. ${ }^{12}$ Subsequently, the EOA was indexed (indexed effective orifice area [EOAi]) to the patient's body surface area.

The threshold for PPM in the aortic position was defined as an EOAi of $\leq 0.85 \mathrm{~cm}^{2} / \mathrm{m}^{2}$, with values from 0.65 to $0.85 \mathrm{~cm}^{2} / \mathrm{m}^{2}$ classified as moderate PPM and those $<0.65 \mathrm{~cm}^{2} / \mathrm{m}^{2}$ as severe PPM.

\section{Surgical Technique}

The surgical approach was either median sternotomy or upper J ministernotomy. Cardiopulmonary bypass was established through cannulation of the ascending aorta and the right atrium using a 2-stage venous cannula. Systemic cooling to a $32^{\circ} \mathrm{C}$ core temperature was performed. Blood cardioplegia at $4^{\circ} \mathrm{C}$ was initiated in an antegrade fashion and repeated through the coronary sinus every 20 minutes. The prosthetic size was selected according to the size of the aortic annulus. The sizing of the annulus was standardized in all cases according to institution protocols. Initially, the annular dimensions were measured using an annulus sizer provided by the manufacturer for the CarboMedics intra-annular valve. In cases in which a 19- or 21-mm actual annulus was measured, the annulus was tested with a Top Hat sizer to check the appropriate position of the supra-annular prosthesis. In those cases, we advocated for the supra-annular prosthesis to make the most of the anatomic area of the native aortic annulus. The only limitation considered when implanting a mechanical supra-annular valve was a low height of the coronary ostia. However, the last decision regarding which prosthesis to use was left to the individual surgeon. Both prostheses were implanted using 2-0 pledgeted mattress sutures with the pledgets placed on the ventricular site of the aortic annulus. Postoperative anticoagulation was performed according to institutional standards.

\section{Follow-up}

The clinical and echocardiographic follow-up data were complete for all surviving patients receiving the Top Hat valve and for $88 \%$ of surviving patients receiving the standard valve after hospital discharge. The data collected included in-hospital mortality, preoperative hemodynamic characteristics, survival and event-free survival, and early and late postoperative hemodynamic characteristics. Echocardiographic studies were performed at discharge from the hospital and at 1 and 5 years of follow-up.

\section{Statistical Analysis}

The data are expressed as the mean \pm standard deviation or median and range, as appropriate. For bivariate analysis, the proportions were compared using contingency tables using the chi-square test and Student $t$ test or Wilcoxon rank sum test were used to compare the mean values of the 2 study groups.

Stepwise forward binary logistic regression analysis was used to confirm or reject the variables on bivariate analysis as risk factors for inhospital mortality. The adjusted odds ratios, $95 \%$ confidence intervals, and $P$ values were derived.

The actuarial estimates of survival were accomplished using KaplanMeier methods. Differences in the probability of survival between the groups were analyzed with the log-rank (Mantel-Cox) test. Stepwise forward Cox regression analysis was used to confirm the independent predictors of long-term survival, which had previously been suggested by bivariate analysis. The adjusted hazard ratios, $95 \%$ confidence intervals, and $P$ values were derived.

The Kolmogorov-Smirnov test showed that the EOAi and LV mass regression did not present a normal distribution. Thus, Spearman analysis was used to test the potential correlation between the EOAi and different postoperative hemodynamic parameters. The study adhered to the Strengthening the Reporting of Observational studies in Epidemiology (STROBE) initiative. ${ }^{14}$ The Statistical Package for Social Sciences statistical program for Windows, version 17.0 (SPSS, Chicago, Ill), was used to perform data analysis.

\section{RESULTS Clinical Results}

The demographic data and clinical risk factors of both groups are listed in Table 1. All patients presented with either pure aortic valve stenosis or mixed aortic valve disease, with aortic stenosis being the dominant lesion. No statistically significant differences were found between the 2 groups $(P=.24$; Table 1$)$.

In the Top Hat group, $20.8 \%$ of the patients had undergone previous cardiac surgery, and in the standard group, $21.8 \%$ of patients had undergone a previous cardiac 
TABLE 1. Demographics, clinical risk factors, and surgical data

\begin{tabular}{|c|c|c|c|c|}
\hline Characteristic & Overall & Top Hat & Standard & $P$ value \\
\hline Age (y) & $62.5 \pm 9$ & $63.7 \pm 7.9$ & $61.9 \pm 9.4$ & .23 \\
\hline $\operatorname{BSA}\left(\mathrm{m}^{2}\right)$ & $1.74 \pm 0.16$ & $1.74 \pm 0.16$ & $1.74 \pm 0.16$ & .85 \\
\hline BMI $\left(\mathrm{kg} / \mathrm{m}^{2}\right)$ & $28 \pm 4.5$ & $27.6 \pm 4.4$ & $28.2 \pm 4.5$ & .42 \\
\hline Male sex & $76(40.9)$ & $22(41.5)$ & $54(40.6)$ & .91 \\
\hline Obesity & $58(31.2)$ & $14(26.4)$ & $44(33.1)$ & .37 \\
\hline \multicolumn{5}{|l|}{ Aortic valve disease } \\
\hline Aortic stenosis & $140(75.3)$ & $97(72.9)$ & $43(81.1)$ & \\
\hline Mixed aortic valve disease (stenosis dominant lesion) & $46(24.7)$ & $36(27.1)$ & $10(18.9)$ & .24 \\
\hline Hypertension & $97(52.2)$ & $20(37.7)$ & $77(57.9)$ & .01 \\
\hline Diabetes mellitus & $36(19.4)$ & $8(15.1)$ & $28(21.1)$ & .35 \\
\hline Hypercholesterolemia & $65(34.9)$ & $14(26.4)$ & $51(38.3)$ & .12 \\
\hline COPD & $23(12.4)$ & $5(9.4)$ & $18(13.5)$ & .44 \\
\hline Atrial fibrillation & $88(47.3)$ & $29(54.7)$ & $59(44.4)$ & .20 \\
\hline Chronic kidney disease & $30(16.1)$ & $6(11.3)$ & $24(18)$ & .26 \\
\hline Coronary artery disease & $42(23.2)$ & $12(25)$ & $30(22.6)$ & .73 \\
\hline Previous stroke & $20(10.8)$ & $10(18.9)$ & $10(7.5)$ & .02 \\
\hline Previous infective endocarditis & $15(8.1)$ & $6(11.3)$ & $9(6.8)$ & .3 \\
\hline Previous cardiac surgery & $40(21.5)$ & $11(20.8)$ & $29(21.8)$ & .87 \\
\hline Additional procedures at AVR & $128(68.8)$ & $37(69.8)$ & $91(68.4)$ & .85 \\
\hline Associated CABG & $25(13.4)$ & $7(13.2)$ & $18(13.5)$ & .95 \\
\hline Logistic EuroSCORE (\%) & $9.6 \pm 10.3$ & $9.3 \pm 10.9$ & $9.9 \pm 8.6$ & .74 \\
\hline Standard EuroSCORE & $6.6 \pm 2.9$ & $6.4 \pm 3$ & $6.9 \pm 2.8$ & .28 \\
\hline Implanted valve size (mm) & & & & NA \\
\hline 19 & $19(10.2)$ & 0 & $19(14.3)$ & \\
\hline 21 & $142(76.3)$ & $28(52.8)$ & $114(85.7)$ & \\
\hline 23 & $25(13.4)$ & $25(47.2)$ & 0 & \\
\hline CPB time (min) & $107.2 \pm 41.3$ & $99.7 \pm 31.8$ & $109.8 \pm 43.9$ & .16 \\
\hline Aortic crossclamp time (min) & $90.6 \pm 32.9$ & $91.1 \pm 34.6$ & $89.1 \pm 27.8$ & .72 \\
\hline Aortic crossclamp time $>90 \mathrm{~min}$ & $85(45.7)$ & $26(49.1)$ & $59(44.4)$ & .56 \\
\hline In-hospital mortality & $20(10.2)$ & $5(9.4)$ & $15(11.3)$ & .71 \\
\hline
\end{tabular}

Data presented as mean \pm standard deviation or n (\%). BSA, Body surface area; $B M I$, body mass index; $C O P D$, chronic obstructive pulmonary disease; $A V R$, aortic valve replacement; $C A B G$, coronary artery bypass grafting; $C P B$, cardiopulmonary bypass.

procedure $(P=.87)$. Combined procedures were performed on $69.8 \%$ of the patients of the Top Hat group (ie, mitral valve replacement in 30 , tricuspid valve repair in 12 , coronary artery bypass grafting in 6, septal myectomy in 3, ascending aorta replacement in 2 , and mitral valve repair in 1). Of the 53 patients in the Top Hat group, 32 underwent $\geq 2$ combined procedures. In contrast, $68.4 \%$ of the patients in the standard group underwent a combined procedure, including mitral valve replacement in 60 , coronary artery bypass grafting in 18 , tricuspid valve repair in 15 , ascending aorta replacement in 9, mitral valve repair in 2 , septal myectomy in 2 , tricuspid valve replacement in 1 , and maze surgery in 1 . Of the 133 patients in the standard group, 17 underwent $\geq 2$ combined procedures.

The mean logistic EuroSCORE was $9.4 \% \pm 10.9 \%$ in the Top Hat group and $9.9 \% \pm 8.5 \%$ in the standard group $(P=.74)$. The mean standard EuroSCORE was $6.4 \pm 3$ in the Top Hat group and $6.9 \pm 2.8$ in the standard group $(P=.28)$.

The operative data are listed in Table 1 . The mean cardiopulmonary bypass time was $99.7 \pm 31.8$ and $109.8 \pm 43.9$ minutes in the Top Hat and standard group, respectively $(P=.16)$. The mean aortic crossclamp time was $91.1 \pm$ 34.6 and $89.1 \pm 27.8$ minutes in the Top Hat and standard groups, respectively $(P=.72)$. Of the 53 patients in the Top Hat group and 133 patients in the standard group, 26 $(49.1 \%)$ and $59(44.4 \%)$ had an aortic crossclamp time of $>90$ minutes $(P=.56)$. An aortic crossclamp time of $>90$ minutes was present for $63.3 \%$ of patients undergoing a concomitant procedure $(P<.001)$ and $65 \%$ (26 of 40$)$ of patients with previous cardiac surgery $(P=.006)$.

The median stay at the intensive care unit was 2 days in both groups (Top Hat group, range 1-10 days; standard group, range $1-46$ days; $P=.36$ ). The median in-hospital stay was also 7 days in both groups (Top Hat group, range, 1-15 days; standard group, range, 1-66 days; $P=.16$ ).

The overall in-hospital mortality was $10.2 \%$. The inhospital mortality was $9.4 \%$ and $11.3 \%$ in the Top Hat and standard groups, respectively $(P=.71)$. In the Top Hat group, 2 patients died of low cardiac output failure, 2 patients of multisystem failure, and 1 patient of perioperative stroke. In the standard group, 8 patients died of 
TABLE 2. Pre- and postoperative hemodynamic data

\begin{tabular}{|c|c|c|c|c|}
\hline Characteristic & Overall & Top Hat & Standard & $P$ value \\
\hline Aortic root diameter $(\mathrm{cm})$ & $3.1 \pm 0.5$ & $3.2 \pm 0.7$ & $3.1 \pm 0.5$ & .17 \\
\hline Indexed aortic root diameter $\left(\mathrm{cm} / \mathrm{m}^{2}\right)$ & $1.8 \pm 0.3$ & $1.8 \pm 0.4$ & $1.8 \pm 0.3$ & .24 \\
\hline Indexed aortic root diameter $<1.5 \mathrm{~cm} / \mathrm{m}^{2}(\%)$ & $40(31)$ & $8(28.6)$ & $32(31.7)$ & .75 \\
\hline Preoperative LVEF $(\%)$ & $61.2 \pm 13.6$ & $59.5 \pm 11.9$ & $61.6 \pm 14$ & .41 \\
\hline Preoperative LV mass (g) & $295.8 \pm 90$ & $330.6 \pm 89.3$ & $282.1 \pm 86.7$ & .001 \\
\hline Preoperative peak transvalvular gradient $(\mathrm{mm} \mathrm{Hg})$ & $67 \pm 32.6$ & $68.6 \pm 34.8$ & $66.6 \pm 32.2$ & .74 \\
\hline $\mathrm{EOA}\left(\mathrm{cm}^{2}\right)$ & $1.48 \pm 0.1$ & $1.55 \pm 0.05$ & $1.45 \pm 0.1$ & $<.001$ \\
\hline Preoperative LVEDD (mm) & $49.2 \pm 9$ & $49.8 \pm 8.8$ & $49 \pm 9.1$ & .66 \\
\hline Preoperative LVESD (mm) & $32.2 \pm 9$ & $33.2 \pm 7.6$ & $32 \pm 9.3$ & .49 \\
\hline Preoperative LVEF $<35 \%$ & $18(9.7)$ & $2(3.8)$ & $16(12)$ & .09 \\
\hline Preoperative severe myocardial hypertrophy & $121(65.1)$ & $42(79.2)$ & $79(59.4)$ & .01 \\
\hline Postoperative LVEF $(\%)$ & $62.7 \pm 11.7$ & $59.7 \pm 12.6$ & $63.7 \pm 11.3$ & .07 \\
\hline Postoperative LV mass (g) & $212.3 \pm 62.1$ & $215.4 \pm 61.8$ & $210.8 \pm 62.4$ & .67 \\
\hline Postoperative peak transvalvular gradient $(\mathrm{mm} \mathrm{Hg})$ & $27.1 \pm 9.6$ & $19.9 \pm 8.9$ & $29.6 \pm 8.6$ & $<.001$ \\
\hline Postoperative LVEDD $(\mathrm{mm})$ & $46.3 \pm 7.7$ & $45.2 \pm 11.1$ & $46.6 \pm 6.3$ & .34 \\
\hline Postoperative LVESD (mm) & $28.1 \pm 10$ & $25.9 \pm 13$ & $28.9 \pm 8.6$ & .11 \\
\hline Postoperative LV mass reduction $(\%)$ & $24.2 \pm 17.4$ & $33 \pm 15.8$ & $20 \pm 16.6$ & $<.001$ \\
\hline
\end{tabular}

$L V E F$, Left ventricular ejection fraction; $L V$, left ventricular; $E O A$, effective orifice area; $L V E D D$, left ventricular end-diastolic diameter; $L V E S D$, left ventricular end-systolic diameter.

multisystem failure, 5 patients of low output cardiac failure, and 2 patients of septic shock.

Bivariate analysis suggested that an aortic crossclamp time of $>90$ minutes, additional procedures at AVR, preoperative severe myocardial hypertrophy, previous cardiac surgery, age $>70$ years, previous infective endocarditis, and chronic kidney disease were risk factors for inhospital mortality. However, logistic regression analysis only confirmed age $>70$ years (odds ratio, $3.959 ; 95 \%$ confidence interval, $1.330-11.783 ; P=.013$ ), aortic crossclamp time $>90$ minutes (odds ratio, 7.374; 95\% confidence interval, 1.984-27.405; $P=.003)$, and severe myocardial hypertrophy (odds ratio, $7.725 ; 95 \%$ confidence interval, $1.005-31.833 ; P=.05$ ) as independent risk factors for inhospital mortality.

\section{Hemodynamic Characteristics}

The hemodynamic and echocardiographic characteristics are listed in Table 2. No statistically significant differences were found in either the aortic root diameter or the indexed aortic root diameter between the 2 groups.

No statistically significant differences were found in the mean preoperative LVEF between the Top Hat $(59.5 \% \pm$ $11.9 \%)$ and standard group $(61.6 \% \pm 14 \% ; P=.41)$.

The mean expected EOAi was significantly greater in the Top Hat group than in the standard group $(0.89 \pm$ $0.08 \mathrm{~cm}^{2} / \mathrm{m}^{2}$ vs $\left.0.85 \pm 0.08 \mathrm{~cm}^{2} / \mathrm{m}^{2}, P<.001\right)$. Of the overall population, 90 patients $(48.4 \%)$ presented with moderate PPM and only 2 with severe PPM. Both patients had received a $19-\mathrm{mm}$ CarboMedics intra-annular prosthesis. One of the patients, who had undergone combined AVR and coronary artery bypass grafting, died 64 months after surgery of prosthetic aortic endocarditis. The other patient, who had undergone combined mitral and AVR, was alive and in New York Heart Association class II at 46 months after surgery. The percentage of patients presenting with PPM was significantly greater in the standard group $(55.6 \%)$ than in the Top Hat group $(34 \% ; P=.008)$.

The mean preoperative LV mass was greater in the Top Hat group $(330.6 \pm 89.3 \mathrm{~g})$ than in the standard group $(282.1 \pm 86.7 \mathrm{~g}, P<.001)$. Likewise, the percentage of patients sustaining severe myocardial hypertrophy was significantly greater in the Top Hat group $(79.2 \%$ vs $59.4 \%$, $P=.01)$. A significantly greater percentage of reduction of LV mass at 5 years of follow-up in the Top Hat group $(33 \% \pm 15.8 \%$ vs $20.1 \% \pm 16.6 \%, P<.001)$. Figure 1 shows the reduction in the LV mass at 5 years of followup in both groups. The mean postoperative peak aortic gradient was lower in the Top Hat group $(19.9 \pm 8.9 \mathrm{~mm}$ $\mathrm{Hg}$ vs $29.6 \pm 8.6 \mathrm{~mm} \mathrm{Hg}, P<.001)$.

Spearman analysis showed a significant positive correlation between the EOAi and the percentage of LV mass reduction (Rho $=0.65, P=.02$ ). However, no significant correlation was found between the EOAi and the postoperative LVEF (Rho $=-0.06, P=.5$ ), postoperative peak aortic transvalvular gradient (Rho $=-0.1, P=.25$ ), postoperative LV end-diastolic diameter (Rho $=-0.23$, $P=.06$ ), and postoperative LV end-systolic diameter (Rho $=-0.14, P=.09$ ).

\section{Long-Term Survival}

The mean follow-up period was $5 \pm 2.9$ years. The overall cumulative survival was $70.3 \%$ and $64.3 \%$ at 5 and 10 years, respectively. The cumulative survival in the Top 


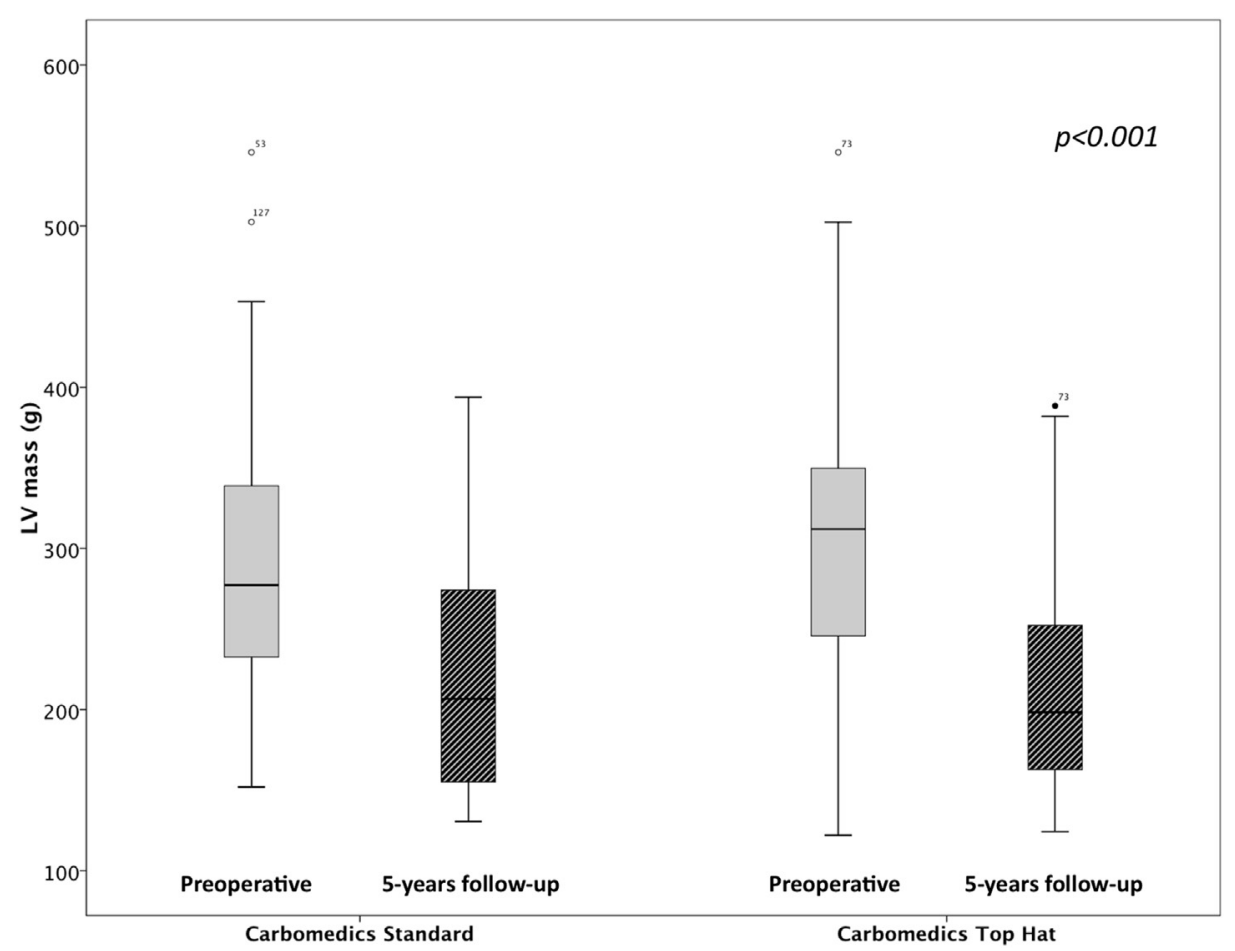

FIGURE 1. Box plot depicting the left ventricular mass preoperatively and at 5 years of follow-up in both groups. $L V$, Left ventricular.

Hat group was $79.7 \%$ and $71.7 \%$ at 5 and 10 years, respectively. In the standard group, the 5-and 10-year survival was $66.8 \%$ and $61.5 \%$, respectively (log-rank test, 0.19 ; Figure 2, A). However, in the subset of patients with severe myocardial hypertrophy $(\mathrm{n}=122)$, the cumulative survival of the Top Hat patients $(n=43)$ was $75.5 \% \pm 7.4 \%$ at 5 and 10 years. In contrast, the survival of the standard valve patients $(\mathrm{n}=79)$ was $52.7 \% \pm 6.6 \%$ at 5 years and $50.1 \% \pm$ $6.8 \%$ at 10 years (log-rank test, 0.04; Figure 2, B).

Freedom from prosthetic valve infective endocarditis in the Top Hat group was $93.3 \% \pm 4.9 \%$ and $84 \% \pm 9.9 \%$ at 5 and 10 years, respectively. Freedom from thromboembolic events at 5 and 10 years in the standard group was $94 \% \pm 2.8 \%$ and $91 \% \pm 3.7 \%$, respectively (log-rank test, 0.85; Figure 3, A). In the Top Hat group, freedom from thromboembolic events was $88.3 \% \pm 5 \%$ at 5 and 10 years. In the standard group, freedom from thromboembolic events was $91 \% \pm 3.1 \%$ at 5 and 10 years (log-rank test, 0.46; Figure 3, $B$ ).

Freedom from aortic valve-related events, including reoperation, in the Top Hat group was $88.3 \% \pm 5 \%$ and $82 \% \pm 7.7 \%$ at 5 and 10 years, respectively. Freedom from aortic valve-related events in the standard group was $85.7 \% \pm 3.8 \%$ and $83.2 \% \pm 4.5 \%$ at 5 and 10 years, respectively (log-rank test, 0.98 ; Figure 4). Only 1 case of prosthetic valve fatal thrombosis occurred in the standard group after 1 year of follow-up. Five reoperations were necessary because of paravalvular leak during follow-up (1 in the Top Hat group and 4 in the standard group).
Cox regression analysis confirmed previous infective endocarditis (hazard ratio, 3.282; 95\% confidence interval, 1.394-7.730), preoperative severe LV dysfunction (hazard ratio, 4.450; 95\% confidence interval, 2.129-9.303), age $>70$ years (hazard ratio, 2.581; 95\% confidence interval, 1.346-4.946), previous stroke (hazard ratio, 2.933; 95\% confidence interval, 1.324-6.499), previous cardiac surgery (hazard ratio, 2.399; 95\% confidence interval, 1.2464.621), and severe myocardial hypertrophy (hazard ratio, 2.559; 95\% confidence interval, 1.095-5.981) as independent predictors of survival. The type of mechanical aortic prosthesis (hazard ratio, $0.662 ; 95 \%$ confidence interval, $0.310-1.413 ; P=.28$ ), concomitant surgery (hazard ratio, 2.067; 95\% confidence interval, 0.931-4.591; $P=.074)$, PPM, and an EOAi of $\leq 0.85 \mathrm{~cm}^{2} / \mathrm{m}^{2}$ (hazard ratio, 1.347 $95 \%$ confidence interval, $0.722-2.514 ; P=.35$ ) were not independent predictors of survival.

\section{DISCUSSION}

In a consistent and consecutive series of patients undergoing AVR with small size mechanical aortic prosthesis, the present study has demonstrated that the supra-annular Top Hat prosthesis has better long-term hemodynamic characteristics than the intra-annular CarboMedics equivalent, with an outstanding greater LV mass regression. It is precisely the challenging subset of patients with severe myocardial hypertrophy in which the Top Hat valve outperformed the standard intra-annular valve in terms of both long-term survival and hemodynamic characteristics. 

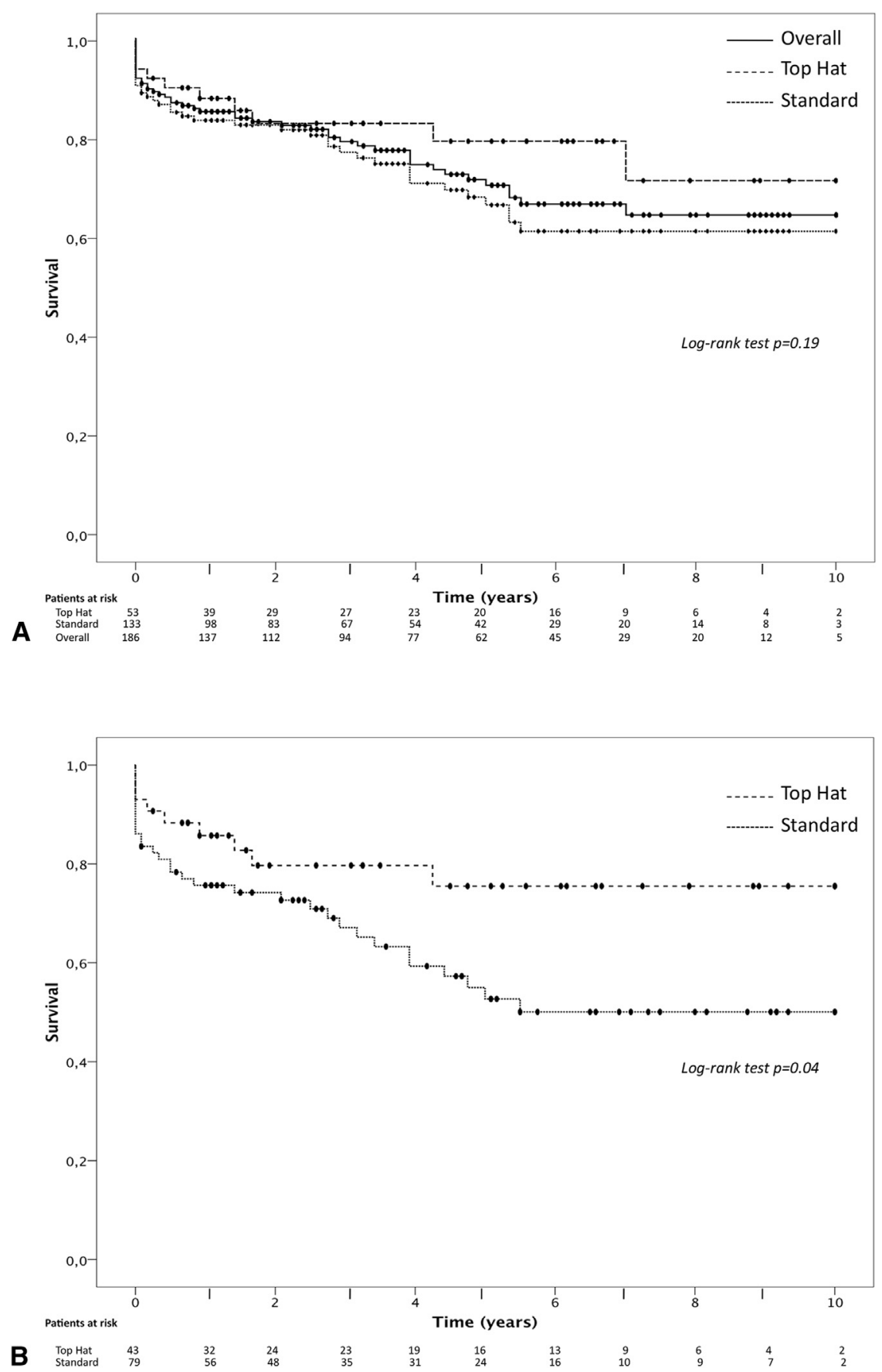

FIGURE 2. A, Overall freedom from mortality and freedom from mortality according to valve type. B, Freedom from mortality in patients with severe myocardial hypertrophy according to valve type.

The LV mass has a strong association with all-cause mortality and cardiovascular events. ${ }^{15}$ The mechanisms accounting for the association of increased LV mass with adverse outcomes could include abnormalities in diastolic function, ${ }^{16}$ ventricular arrhythmias, ${ }^{17}$ and myocardial ischemia due to an imbalance between the demand and supply of oxygen to the myocardium. ${ }^{18}$ We actually confirmed that severe LV hypertrophy is a strong independent predictor of long-term survival.

The Top Hat valve presented with a remarkably greater EOAi, which was ultimately associated with greater postoperative LV mass regression. Nonetheless, the better hemodynamic performance of the Top Hat valve did not entail significantly better long-term survival in the overall 

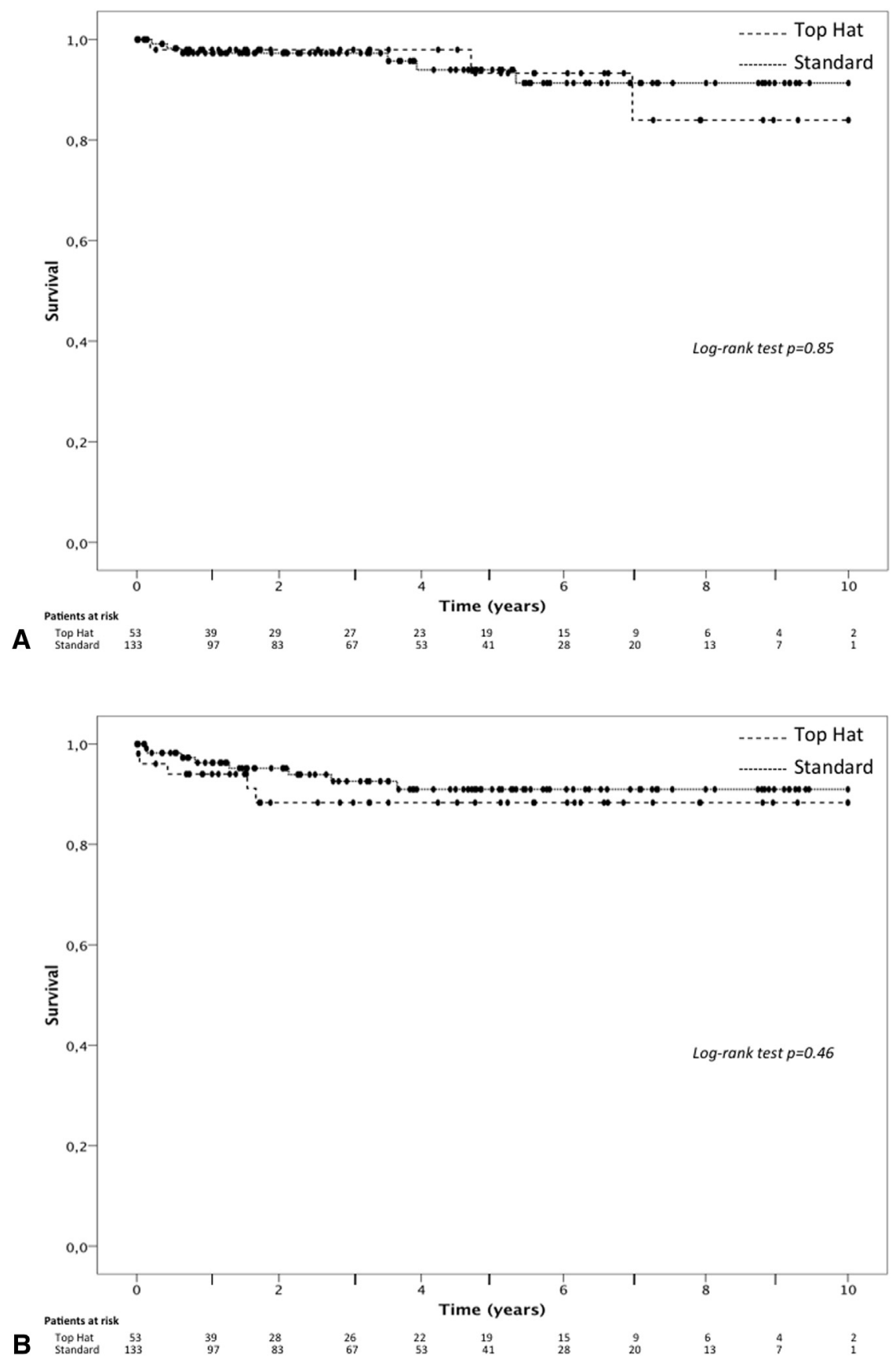

FIGURE 3. A, Freedom thromboembolic events according to valve type. B, Freedom from endocarditis according to valve type.

population with the small aortic root. The type of mechanical aortic prosthesis was not an independent predictor of mortality in the overall population. In contrast, in the subset of patients with severe myocardial hypertrophy, the Top Hat valve demonstrated remarkably greater long-term survival than the standard valve (log-rank test, 0.04). The lower incidence of hypertension in the Top Hat patients might have played a role in the improved postoperative LV mass regression. In contrast, it should also be highlighted that the preoperative LV mass was significantly greater in the Top Hat group than in the standard group, suggesting that the degree of preoperative LV hypertrophy was mainly conditioned by aortic valve stenosis rather than by hypertension.

Other investigators have previously highlighted that the supra-annular Top Hat valve provides an advantage of 1 to 2 sizes compared with the intra-annular valve, thus improving the effective valve opening area. ${ }^{4,5,19}$ In our series, the mean expected EOAi was significantly greater in the Top Hat group than in the standard group. Spearman analysis showed a significant positive 


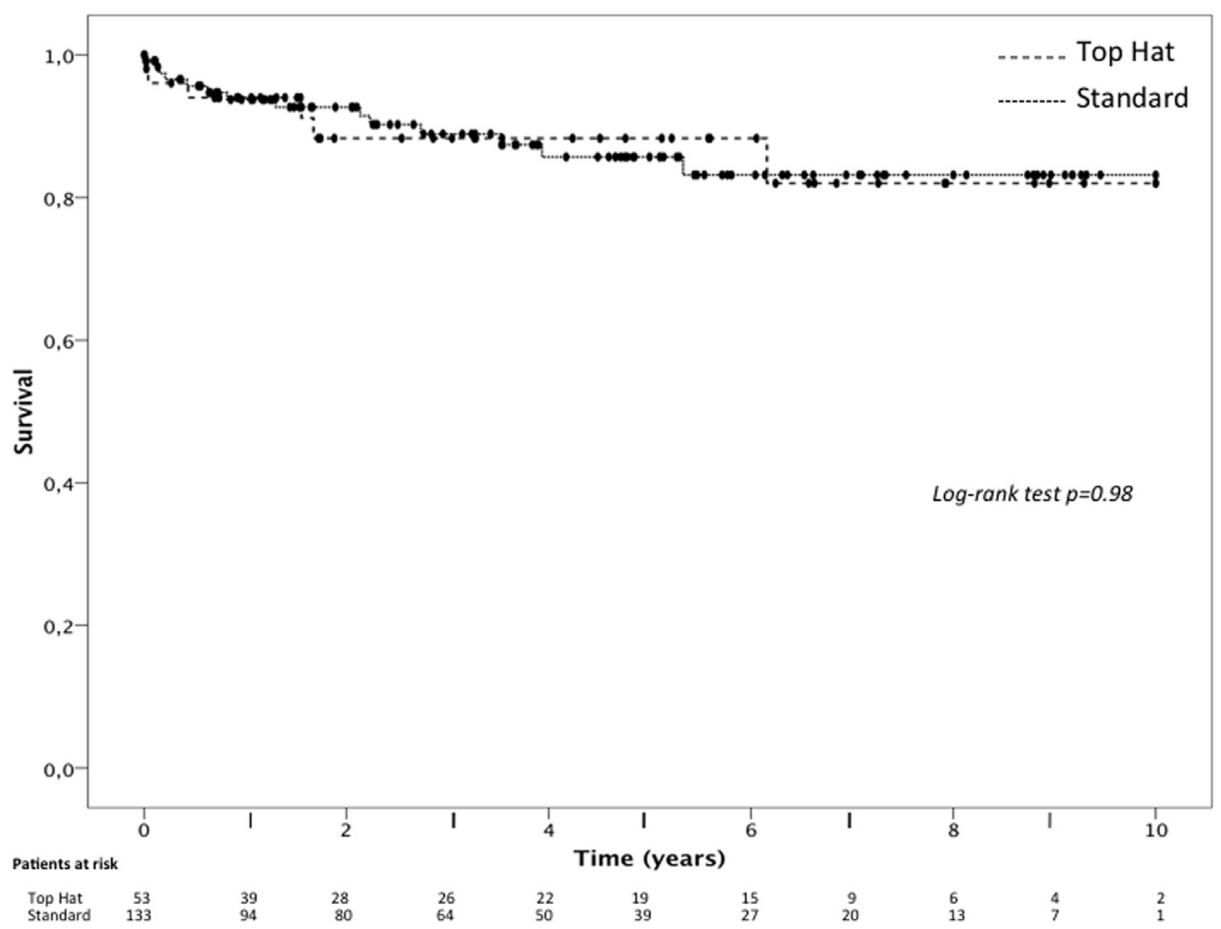

FIGURE 4. Freedom from aortic-related events, including paravalvular leaks and reoperation, according to valve type.

correlation between the EOAi and the percentage of LV mass reduction.

PPM has been reported to increase perioperative mortality and reduce postoperative survival in patients undergoing AVR. ${ }^{20-22}$ Nevertheless, other investigators have claimed that patients with PPM have similar early and late postoperative survival rates. ${ }^{23-26}$ In our series, only 2 patients presented with severe PPM; however, moderate PPM was predicted in $48.4 \%$ of the patients. However, Cox regression analysis did not identify an EOAi of $\leq 0.85 \mathrm{~cm}^{2} / \mathrm{m}^{2}$ as an independent predictor of mortality.

The rate of comorbidities in our population was significant, as highlighted by the number of additional procedures at AVR in our series. Almost $70 \%$ of patients underwent concomitant surgery. Moreover, $21.5 \%$ of them had already undergone previous cardiac surgery. The preoperative expected mortality increased to $9.6 \% \pm 10.3 \%$, as estimated by the logistic EuroSCORE. However, our in-hospital mortality was $9.4 \%$ and $11.3 \%$ in the Top Hat and standard groups, respectively. Actually, the difference between our in-hospital mortality and those reported in other series with similar high-risk populations was negligible. ${ }^{6}$

It has been suggested that supra-annular valves, including the Top Hat valve, should be avoided if the coronary ostia are placed downward in the aortic sinus. ${ }^{27}$ Several cases of coronary ostia obstruction after AVR with the Top Hat valve have been reported. ${ }^{6,28} \mathrm{~A}$ particular fact to be stressed was that we did not observe any functional obstruction of the coronary ostia in our series, even when the supra-annular valve was used in $51.7 \%$ of the double valve replacement surgeries and $20.8 \%$ of redo surgeries in which an small aortic root is remarkably rigid and fibrotic.

The long-term results of both types of aortic prosthesis were comparable with those of other series in both groups. ${ }^{6,25}$ The cumulative survival in the Top Hat group was slightly better at 5 and 10 years than that in the standard group; however, this difference did not reach statistical significance. The better hemodynamic performance and greater LV mass regression in the Top Hat group might have been responsible for this finding; however, the limited number of patients in the Top Hat group precluded a formal conclusion in this matter.

Both groups also presented with a low rate of thromboembolic and aortic valve-related events during the followup period. Just as other investigators have previously pointed out, ${ }^{6,25}$ this fact reflects the favorable hemodynamic behavior of both valves themselves.

Cox regression analysis confirmed previous infective endocarditis, preoperative severe LV dysfunction, age $>70$ years, previous cardiac surgery, previous stroke, and severe myocardial hypertrophy to be independent predictors of survival. Age and LV dysfunction have previously been highlighted as predictors by other investigators. ${ }^{6,25,28}$

\section{Study Limitations}

The present study had the limitations inherent to any retrospective study. The primary limitation was that the choice of the aortic valve prosthesis was left to the surgeon's discretion; therefore, the compared valve types were not 
randomly assigned. Nevertheless, it should be highlighted that the Top Hat was used as a last resort choice when the presence of severe myocardial hypertrophy or a hazardous small aortic root discouraged the use of a standard prosthesis. The study reported the expected iEOAs, which were calculated from the patients' body surface area and each prosthesis theoretical EOA value as provided by the manufacturer, rather than the actual iEOA measured on the predischarge echocardiogram. Although the preoperative LV mass was greater in the Top Hat group, we compared the relative LV mass reductions (in percentages) and not the absolute values (in grams), thus, amending that potential shortcoming.

The patient population in the present study clearly reflected the whole clinical spectrum of patients with a small aortic root undergoing AVR, including the daunting subset of patients with previous aortic surgery, concomitant procedures, and severe myocardial hypertrophy. The results of the present study were from a limited single-center experience, thereby requiring a multicenter study for the results to be validated.

Finally, the number of patients who reached the 10-year follow-up point was small. Therefore, future studies should incorporate data from a larger number of patients acquired during a longer follow-up period.

\section{CONCLUSIONS}

Patients undergoing aortic AVR with a small mechanical aortic prosthesis and other concomitant cardiac procedures constitute a high-risk subset of patients that entails not negligible surgical mortality, especially when severe myocardial hypertrophy is associated. Nonetheless, the clinical and hemodynamic long-term results have been satisfactory.

Given that the Top Hat valve hemodynamically surpasses the intra-annular valve, we suggest the use of the supraannular Top Hat prosthesis can be especially recommended for patients with a small aortic root and severe myocardial hypertrophy. This particular challenging subset of patients will be the ideal target for the supra-annular mechanical CarboMedics valve.

\section{References}

1. Rahimtoola SH. The problem of valve prosthesis-patient mismatch. Circulation. 1978;58:20-4.

2. Pibarot P, Dumesnil JG, Lemieux M, Cartier P, Metras J, Durand LG. Impact of prosthesis-patient mismatch on hemodynamic and symptomatic status, morbidity and mortality after aortic valve replacement with a bioprosthetic heart valve. J Heart Valve Dis. 1998; 7:211-8.

3. Pibarot P, Dumesnil JG. Prosthesis-patient mismatch: definition, clinical impact, and prevention. Heart. 2006;92:1022-9.

4. Roedler S, Moritz A, Wutte M, Hoda R, Wolner E. The CarboMedics "top hat" supraannular prosthesis in the small aortic root. J Card Surg. 1995;10:198-204.

5. Bernal JM, Martin-Duran R, Rabasa JM, Revuelta JM. The CarboMedics "TopHat" supraannular prosthesis. Ann Thorac Surg. 1999;67:1299-303.

6. Roedler S, Czerny M, Neuhauser J, Zimpfer D, Gottardi R, Dunkler D, et al. Mechanical aortic valve prostheses in the small aortic root: Top Hat versus standard CarboMedics aortic valve. Ann Thorac Surg. 2008;86:64-70.
7. Sahn DJ, DeMaria A, Kisslo J, Weyman A. Recommendations regarding quantitation in M-mode echocardiography: results of a survey of echocardiographic measurements. Circulation. 1978;58:1072-83.

8. Devereux RB, Alonso DR, Lutas EM, Gottlieb GJ, Campo E, Sachs I, et al. Echocardiographic assessment of left ventricular hypertrophy: comparison to necropsy findings. Am J Cardiol. 1986;57:450-8.

9. Lang RM, Bierig M, Devereux RB, Flachskampf FA, Foster E, Pellikka PA, et al Recommendations for chamber quantification: a report from the American Society of Echocardiography's Guidelines and Standards Committee and the Chamber Quantification Writing Group, developed in conjunction with the European Association of Echocardiography, a branch of the European Society of Cardiology. J Am Soc Echocardiogr. 2005;18:1440-63.

10. Baumgartner H, Hung J, Bermejo J, Chambers JB, Evangelista A, Griffin BP et al. Echocardiographic assessment of valve stenosis: EAE/ASE recommendations for clinical practice. J Am Soc Echocardiogr. 2009;22:1-23, quiz 101-2.

11. Zoghbi WA, Enriquez-Sarano M, Foster E, Grayburn PA, Kraft CD, Levine RA, et al. Recommendations for evaluation of the severity of native valvular regurgitation with two-dimensional and Doppler echocardiography. J Am Soc Echocardiogr. 2003;16:777-802.

12. Chambers J, Cross J, Deverall P, Sowton E. Echocardiographic description of the CarboMedics bileaflet prosthetic heart valve. J Am Coll Cardiol. 1993;21: 398-405.

13. Dumesnil JG, Honos GN, Lemieux M, Beauchemin J. Validation and applications of indexed aortic prosthetic valve areas calculated by Doppler echocardiog raphy. J Am Coll Cardiol. 1990;16:637-43.

14. von Elm E, Altman DG, Egger M, Pocock SJ, Gotzsche PC, Vandenbroucke JP Strengthening the Reporting of Observational Studies in Epidemiology (STROBE) statement: guidelines for reporting observational studies. BMJ. 2007;335:806-8.

15. Bouzas-Mosquera A, Broullon FJ, Alvarez-Garcia N, Peteiro J, Mosquera VX Castro-Beiras A. Association of left ventricular mass with all-cause mortality, myocardial infarction and stroke. PLoS One. 2012;7:e45570.

16. Yarbrough WM, Mukherjee R, Ikonomidis JS, Zile MR, Spinale FG. Myocardial remodeling with aortic stenosis and after aortic valve replacement: mechanisms and future prognostic implications. J Thorac Cardiovasc Surg. 2012;143:656-64.

17. Wolk R. Arrhythmogenic mechanisms in left ventricular hypertrophy. Europace. 2000;2:216-23.

18. Houghton JL, Frank MJ, Carr AA, von Dohlen TW, Prisant LM. Relations among impaired coronary flow reserve, left ventricular hypertrophy and thallium perfusion defects in hypertensive patients without obstructive coronary artery disease. J Am Coll Cardiol. 1990;15:43-51.

19. Lundblad R, Hagen OM, Smith G, Kvernebo K. The CarboMedics supraannular top hat valve improves prosthesis size in the aortic root. J Heart Valve Dis. 2001; 10:196-201

20. Blais C, Dumesnil JG, Baillot R, Simard S, Doyle D, Pibarot P. Impact of valve prosthesis-patient mismatch on short-term mortality after aortic valve replacement. Circulation. 2003;108:983-8.

21. Walther T, Rastan A, Falk V, Lehmann S, Garbade J, Funkat AK, et al. Patient prosthesis mismatch affects short- and long-term outcomes after aortic valve replacement. Eur J Cardiothorac Surg. 2006;30:15-9.

22. Rabus MB, Kirali K, Kayalar N, Mataraci I, Yanartas M, Ulusoy-Bozbuga N et al. Effects of patient-prosthesis mismatch on postoperative early mortality in isolated aortic stenosis. J Heart Valve Dis. 2009;18:18-27.

23. Mascherbauer J, Rosenhek R, Fuchs C, Pernicka E, Klaar U, Scholten C, et al. Moderate patient-prosthesis mismatch after valve replacement for severe aortic stenosis has no impact on short-term and long-term mortality. Heart. 2008;94:1639-45.

24. Vicchio M, Della Corte A, De Santo LS, De Feo M, Caianiello G, Scardone M, et al. Prosthesis-patient mismatch in the elderly: survival, ventricular mass regression, and quality of life. Ann Thorac Surg. 2008;86:1791-7.

25. Bernal JM, Lorca J, Prieto-Salceda D, Pulitani I, Pontón A, García I, et al. Per formance at 10 years of the CarboMedics "Top-Hat" valve: postclamping time is a predictor of mortality. Eur J Cardiothorac Surg. 2006;29:144-9.

26. Howell NJ, Keogh BE, Ray D, Bonser RS, Graham TR, Mascaro J, et al. Patientprosthesis mismatch in patients with aortic stenosis undergoing isolated aortic valve replacement does not affect survival. Ann Thorac Surg. 2010;89:60-4.

27. de Brux JL, Subayi JB, Binuani P, Laporte J. Doppler-echocardiographic assessment of the CarboMedics supra-annular "Top-Hat" prosthetic heart valve in the aortic position. J Heart Valve Dis. 1996;5(Suppl 3):S336-8.

28. Gillinov AM, Blackstone EH, Alster JM, Craver JM, Baumgartner WA Brewster SA, et al. The CarboMedics Top Hat supraannular aortic valve: a multicenter study. Ann Thorac Surg. 2003;75:1175-80. 
TABLE E1. Effective orifice area for each valve type and size as provided by the manufacturer

\begin{tabular}{lcc}
\hline $\begin{array}{c}\text { Prosthesis } \\
\text { nominal size }\end{array}$ & $\begin{array}{c}\text { CarboMedics } \\
\text { standard EOA }\left(\mathbf{c m}^{\mathbf{2}}\right)\end{array}$ & $\begin{array}{c}\text { CarboMedics } \\
\text { Top Hat EOA }\left(\mathbf{c m}^{\mathbf{2}}\right)\end{array}$ \\
\hline 19 & 1.0 & 1.0 \\
21 & 1.5 & 1.4 \\
23 & 1.6 & 1.9 \\
\hline EOA, Effective orifice area. &
\end{tabular}

